\title{
sciendo
}

DOI 10.2478/sbe-2019-0052

SBE no. 14(3) 2019

\section{SEVERAL CONTEMPORARY ECONOMY FEATURES, CONSEQUENCES OF INTERNET EXPANSION AND I.C.T. INNOVATIONS IN THE WORLD}

\author{
ȘERBU RĂZVAN \\ Lucian Blaga University of Sibiu, Romania
}

\begin{abstract}
:
The Internet has reach half of the population of the planet and in the latest three years more than 700 millions users came on line from the emerging world. Most of them are coming now from the poorer population. This it may be a turning point for their economic development. This paper attempts to outline some possible future developments of the contemporary economy within the new digital transformation and development of internet firms in emerging markets, some of the pluses and minuses, some of the opportunities and threats brought by the expansion of the Internet and information and communication technologies at different levels. We will present some significant aspects about this impact for individuals and for companies especially in Eastern Europe but also around the world. The study intends to deliver also analysis at the level of governmental reactions. Governments have gone through different sentiments that have led to different responses to these technologies. A new revolution that is about to begin it will be grounded on blockchain the technologies that cryptocurrencies are based on. What was initially translated as a threat to governments and central banks can become a solution if it's deal cautiously.
\end{abstract}

Key words: information and communications technology, central banks, cryptocurency

\section{Introduction}

"At a time of slowed growth and continued volatility, many countries are looking for policies that will stimulate growth and create new jobs. Information communications technology (ICT) is not only one of the fastest growing industries - directly creating millions of jobs - but it is also an important enabler of innovation and development. In OECD countries, more than $95 \%$ of businesses have an online presence. The Internet provides them with new ways of reaching out to customers and competing for market share. The unprecedented explosion of connected devices throughout the world has created new ways for businesses to serve their customers" (Elena Kvochko, 2013).

A remarkable number from the richest persons from the top Forbes are performing within the tech industry, and this number is becoming bigger and bigger every year now. This is telling us that the interest of businesses in this area is increasing and the dynamic 
should receive more interest. The data coming out is supporting this dynamic and affecting all levels of society.

The American business magazine "Forbes" reports is well appreciated in the world for its articles but also for the rankings Forbes Global 2000, Forbes 400 and other rankings that are publish every year.

\section{Good practice examples}

"Managers/investors/shareholders need to know more about business sustainable competitiveness because not only revenues or net income are important in order to classify companies (see Global Fortune 500) in terms of their long-run competitiveness" (Herciu \& Ogrean, 2018)

"The notion of 'smart city' is a response to these problems; it has gained popularity over the past few years. Many cities define themselves as "smart" when they identify some of their own characteristics as being so (such as broadband connectivity, digital inclusion, and knowledge workforce)" (Jianjun Sun et al., 2016). Withal, "a common underlying fact is that these smart cities benefit from innovative applications of new kinds of information and communications technology (ICT) to support communal sharing" (Agyeman \& McLaren, 2014, apud Jianjun Sun et al., 2016).

We will present here very briefly some examples of success that came from Eastern Europe, Romania, to underline the possibilities and opportunities that the new technologies provide nowadays.

A very good example in this regard is a Romanian programmer Daniel Dines, the founder of an IT company, which is at the top of the ranking of the richest Romanians. Forbes dedicates an extensive article to him and places the Romanian himself on the cover of the American edition of the magazine, which calls him "the bot boss". His company has become a world leader in the field of boting, a type of artificial intelligence, and is valued at $\$ 7$ billion.

He now runs a leading company in his field, headquartered in a skyscraper in Manhattan, with over 30 offices worldwide and over 3,200 employees. Daniel Dines is 47 years old and has reached a fortune of 1.4 billion dollars, surpassing the former number one of Romanian in top Forbes for many years, Ion Tiriac, whose fortune is estimated at 1.1 billion.

Another example of the impact of new technologies for the evolution of small and medium enterprises, could be the company "Softvision", a company founded in Cluj Napoca, with branches in Bucharest, lasi, Timisoara, Baia Mare, but also in the USA (Silicon Valley and Las Vegas), was bought by Cognizant an American company. The value of the transaction it was about $\$ 550$ millions.

The transaction is a spectacular one and announces a period of growth for the company and for other partners from the group. It was a spectacular step in the history of Softvision, a history that began in Cluj-Napoca, Romania. The owner specified that" Our path will continue to be steeply uphill as well as in this spearheading role of Cognizant Digital Business. Our success is based entirely on the unmatched expertise of our software 
engineers in Romania, and now Cognizant will bring us the global scale we needed. We will continue to offer state-of-the-art software solutions for the world's major brands."

"Few times in history have rapid advancements in technology and breakthrough innovations had the ability to disrupt retail business models in such fast and all encompassing ways. If not already, the Internet of Things, artificial intelligence, augmented and virtual reality (AR/VR), and robots should be on every retailer's radar" (Deloite, 2018).

If at the level of small and medium companies the impact is quite significant we can notice an exponentially grow at the level of the big businesses. The very famous company Amazon, Google, Apple, Facebook and a few others, owe their success to the expansion of internet and the new technologies.

The top five companies in the US have suffer an impressive change in the fast forward ten years from 2008 to 2018. In ten years, Apple has become number one winning more than fifteen places and fighting continues for the first position in top, with Microsoft and Alphabet. From the beginning "Apple's strategy it was also ambitious when it comes to the pursuit of opportunities to create demand for its products in the global market. Apple's Strategy is to expand into international markets when domestic markets mature and the new opportunities in consuming smart phone and tablet products due to the growth of technology and the economy" (Johnson, Katherine, et al, 2012). Another example that sustains our thesis is Facebook, which was only founded in 2004 is already in top 5th largest company in the world.

It is worth mentioning here that are many examples like the dynamic of Instagram that in a short period of time like 20 month, grow as a company from a couple of employees and not a cent profit to be worth a billion dollars, more precisely to be bought at this price huge price just 551 days after launch. Who knows what changes could made to this top and what could happen if they were not bought rapidly by Facebook.

\section{The impact of the new technologies}

A new revolution is here to come, and it has a modern foundation in blockchain that seems a key opportunity especially for young and small company more than it is for the big one. As the internet brought a revolution, the same is about to begin now with blockchain.

The impact of the new technologies is not felt just at the level of companies but more than ever at the government level. Governements have gone through different sentiments that have led to different responses to these technologies. From an economic point of view, it has been noticed that adoption of the new technology did not have immediate results in increasing productivity and gross domestic product, and this has confused their forecasts and intervention measures, both for themselves and especially for the central banks, and from a political perspective they did not saw with good eyes those technological discoveries so at the beginning they tried to defend and obstruct them. But the censorship, especially in democratic regimes, were the population react fast, has been easier said than done.

Here are a few things that should be worrying, like 30 governments used Internet manipulation techniques just a year ago, distort online information, and worse than the 
previous year when the figure was just twenty-three. So with every passing year, governments can not keep away those technologies so they start to use them in their favor using them in order to manipulate the masses.

"The aspects of digital strategy companies will emphasize over the next years depend heavily on the industry, size and location of the individual company. Financial services companies are more likely to stress $\mathrm{Al} /$ machine learning $(57 \%)$ and blockchain (51\%) while, for manufacturing companies, cloud computing $(50 \%)$ and loT $(48 \%)$ are especially important" (The Economist Intelligence Unit, 2019).

As a good practice example in this regards, we should mention the Walmart use of artificial intelligence camera technology a couple of years ago. They start on their own solution, based on artificial intelligence and also face recognition technology. The system can find errors or theft if an item is not scan and it is placed in shopping bag directly without paying it. Even more than this, some camera determine the mood of each customer while shopping, and can measure customer satisfaction immediately after visiting a supermarket. Walmart is generally well known in the world as a pioneer in many directions, so we can expect and it is only a matter of time until other businesses will use this new revolutionary technology.

Thus, if the system finds a customer with an unhappy or happy face, the store employee will be notified. This innovation will help improve its customer services and increase customer satisfaction. After all, the employee will be able to quickly respond to customer dissatisfaction and help them solve the problem as quick as possible. Also, as in e-commerce where the clicks are analyzed this system for the real environment will help to analyze the behaviour of customers in a certain period.

This innovative service can compare customers' satisfaction with what they buy and how much they spend, to provide the best cost-benefit ratio for each level of their income. This can help in changing the habits of different customers according to the budget and the expenses for shopping.

"In a world governed by complex financial and economic systems, knowing the process of financial intermediation becomes a must. We face times when the process of financial intermediation seems to change nearly as a natural phenomenon. Financial intermediation stakeholders find constantly new ways to interact on behalf of obtaining funds they need and returns they expect" (Renate Bratu, 2018).

A new threat is now in full swing [...] cryptocurrencies. But what was initially translated as a threat to governments and central banks can become a solution if it's deal cautiously. In this regard, however, it is necessary; first of all, some knowledge refreshes in order to rebuild the bankers who have not recently graduated a program of higher education.

Although "there is nothing new under the sun" as the book of books tells us or as Eminescu says "all is old and all is new", it is important to be better prepared with both the examples of the past and the notions of the present but also with the opportunities and threats of the future. It is said more and more often: "Let's read Kindlerberger", and even though it has become an aphorism strongly recommended to be read and re-read, the reputed Charles Kindleberger. He has specialized in economic history and is the author of over thirty books and an important architect of the Marshall Plan. In 1945-1947 he served 
as principal in the United States Department of State in the Bureau for Economic Security and in 1947-1948, he was an advisor to the European Recovery Program.

In 1978 he writes "Manias panics and crashes" a book that is reissued after every crisis, both after the "dot-com" crisis of 2000 and after the global economic crisis of 2007. It seems that not many have read it and do not know this aphorism.. "Let's read Kindlerberger" and because of this the world is condemned to re-edit it.

Kindlerberger presents several attempts throughout history in different centuries have been the same attempts to find innovative ways to increase the money supply. From the simple traders who wrote loan papers to the kings who were beating new currency on different occasions and sometimes modifying the composition or by spoiling, it multiplied just because it satisfied their creditors.

Therefore, this temptation to issue currency has existed since ancient times to electronic and cryptocurrencies. Murray N. Rothbard, in The Mystery of Money, says that whoever issues the currency holds the power, at any time (Murray N. Rothbard et all, 2008).

In 1776 Adam Smith captures in his work the Wealth of Nations some ideas which are very well synthesized in the edition republished after 200 years, in his introduction by Tom Butler-Bowdon: "In the section on banks, Smith shows us how their development is beneficial to society, especially by the way paper money, which represents the real means of exchange - gold and silver -, makes the wheel of an economy easier to return and at lower costs. He pays tribute to the invention of current bank accounts, which helps people no longer have to keep money in their safe deposit boxes and makes business transactions much easier, but also the ease of account discovery, which allows manufacturers to always have they have enough money to pay for the materials when they need them and to pay the suppliers, even before their own bills are paid. "The essential point about national wealth is that it grows when things and money are circulated and exchanged. This was understood by the medieval European cities such as Florence, which amassed huge riches not by doing business simply with the countryside surrounding them, but with the most remote corners of the globe" (Tom Butler-Bowdon, 2008).

Smith notes that a paper money company is building its "highway" suspended above the current economy, which will speed up its business activity. The easier the money flows, the better the quality and depth of the banking system at the service of society, the more prosperous a nation will be. "But if this economic engines are too accelerated on this highway, this can lead to even more terrible accidents. This increase the importance and the know-how of the functions and importance of money because the money makes the company work and evolve, so that we can enjoy what we have today, and we are also addressing here to the Fin-Tech field.

The impact of the new technologies goes farther and is affecting nowadays the correlation between inflation and economic development. In the developed economy despite the growing income, a boost in some prices it will not be so simply accepted because with the Internet expansion other solutions for that require can be straightforwardly found, so the equilibrium price, the intersection of the demand and supply curves could not be affected as usual. 
In spite of a continuous multiplication of money and the decrease of the main earth's resources the inflation in the developed economy is under the expectation, and these entitle the central banks to be more and more worried and to find solutions to balance that.

The temptation to print too much money has always existed, especially when it came to private finance. The role of central banks has been quite clear so far, when a new wave is on the horizon. As if it was not enough for the financial market to record a growing percent of a "peer-to-peer" lending and the loans are more often found outside the private banks through online services that match lenders with borrowers, now, we have this new wave. Cryptocurrencies are based on a great discovery that worth all the appreciation: the "blockchain". This discovery is only now beginning to be made widely known and used, with P2P ("peer-to-peer") invasion in economics, politics, and society, and this is going to be huge, really huge in the near future.

This discovery was described, in an early form, by a secure chain of information blocks in 1991 by Stuart Haber and Scott Stornetta. But for the first time this "blockchain" was conceptualized by a person (or a group of people suspected) who wanted to name himself Satoshi Nakamoto and who in 2008 created "bitcoin" a decentralized cryptocurrency that did not belong to any central bank, to any state, but is retained only on the computers of those who make available this resource, for a reward. These are called miners and have the role of securing and recognizing any information that appears in the chain about bitcoin. If someone tries to modify something to counterfeit this currency, it conflicts with the "blockchain" kept on most of the participants' computers that validate this information.

"A purely peer-to-peer version of electronic cash would allow online payments to be sent directly from one party to another without going through a financial institution. Digital signatures provide part of the solution, but the main benefits are lost if a trusted third party is still required to prevent double-spending" (Nakamoto Satoshi, 2008).

\section{Conclusion}

If the central banks were worried about this Bitcoin and were preparing to regulate this currency, some banks would reject it even through bans; others would trade it, because the cryptocurrency market has become extremely crowded and with each passing day new cryptocurrencies appear.

There are more and more states even intending to issue even this kind of coins, so the phenomenon gives rise to an increasing dispute that is worth pursuing. The tension that has been put on them by central banks will not remain unanswered, because we must not forget the laws of the great Isaac Newton and more precisely the third principle of mechanics: "When on object exerts on another object a force (called force of action), the second object also exerts on the first one a force (called a reaction force) of the same magnitude but in the opposite direction".

The rate at which the Internet penetration has increased has both a positive impact and a less luminous part regarding the impact on the population by manipulating and 
abusive intervention in the decision-making process or even overcoming the democratic barriers through the excessive involvement of public institutes.

The new wave resulting from the analysis of large data volumes and the dynamics of artificial intelligence has made it possible to gather, combine, analyze and store indefinitely large volumes of data. In recent years, a dominant business model has emerged for most web services, which is based on tracking people online and collecting data on their character, health, relationships and thoughts and opinions in order to generate revenue from digital advertising.

\section{References:}

Agyeman J, McLaren D (2014), 'Smart Cities' Should Mean 'Sharing Cities', Time magazine, September 29, available at: https://time.com/3446050/smart-cities-should-mean-sharing$\underline{\text { cities/ }}$

Bratu Renate, (2018), Financial Intermediation in Modern Europe Time: Evidence from Romania, Emerging Issues in the Global Economy, Springer Proceedings in Business and Economics, pp.61-82

Butler-Bowdon Tom, (2008), 50 Prosperity Classics, attract it, create it, manage it, share it, wisdom from the best books on wealth creation and abundance, Nicholas Brealey Publishing, p.263

Deloitte, (2018), Global Powers of Retailing 2018 Transformative change, reinvigorated commerce, available at: https://www2.deloitte.com/content/dam/Deloitte/at/Documents/aboutdeloitte/global-powers-of-retailing-2018.pdf

Elena Kvochko (2013), Five ways technology can help the economy, World Economic Forum Agenda; available at : https://www.weforum.org/agenda/2013/04/five-ways-technology-canhelp-the-economyl

Herciu Mihaela, Ogrean Cludia (2018), Business Sustainable Competitiveness a Synergistic, LongRun Approach of a Company's Resources and Results, Studies in Business and Economics, Volume 13; Issue 3, pp. 26-44

Jianjun Sun, Jiaqi Yan, Kem Z. K. Zhanget , (2016), Blockchain-based sharing services: What blockchain technology can contribute to smart cities, Financial Innovation, Financial Innovation volume 2, Article number: 26, pp. 1-9

Johnson, Katherine; Li, Yang; Phan, Hang; Singer, Jason; and Trinh, Hoang, (2012) "The Innovative Success that is Apple, Inc.", Theses, Dissertations and Capstones, Marshall University, Marshall Digital Scholar, p 418 ,

Murray N. Rothbard, (2008), The Mystery of banking, second edition, Ludwing von Mises Institute, Alabama

Nakamoto, Satoshi (2008). "Bitcoin: A Peer-to-Peer Electronic Cash System" (PDF). bitcoin.org. Archived (PDF) from the original on 20 March 2014. Retrieved 28 April 2014, available at: https://bitcoin.org/bitcoin.pdf

The Economist Intelligence Unit, (2019): The year of digital decisions, The Economist Intelligence Unit Limited, available at:

https://assets1.dxc.technology/digital transformation/downloads/Digital Decisions Survey Report.pdf 